\title{
An Analysis of Power Enhancement of Gas Turbine Power Plant Using Different Types of Air Cooling System
}

\author{
D. Muthukumaran .ME (Thermal) \\ Junior Engineer (Mech), Puducherry Power Corporation Limited, Karaikal, India
}

\begin{abstract}
Gas Turbines are constant volume machines and their power output is directly proportional and limited by the air mass flow rate entering the turbine. The increase in ambient temperature can results in decrease of air density, and consequently in the reduction of the mass flow rate. Thereby mass flow rate of air passes through the turbine and power output is reduced especially in summer months. This is a major negative aspect of gas turbines operating in a tropical country like India. Karaikal is a major port city of East Coast of India where this study was carried out, where the ambient temperature typically varies between $28^{\circ} \mathrm{C}$ and $38^{\circ} \mathrm{C}$. In this study the performance enhancement of Puducherry power Corporation power plant located in karaikal, Union Territory of Pondicherry Gas turbine is thermodynamically analyzed by suggesting cooling the compressor intake air with different type of cooling methods. There are two basic systems currently available for inlet cooling. The first and most common system used in Gas turbine inlet air cooling is evaporative cooling system. The second system involves application of absorption type chiller to cool the inlet air before entering in to the axial flow compressor. In the present work, a thermodynamic analysis of gas turbine performance is carried out to calculate compressor work, power output and thermal efficiency at different inlet air temperature condition. The cooled air being denser gives the machine a higher mass flow rate, resulting in an increase in turbine output and efficiency. After the application of above two methods of cooling system, the corresponding results are compared and finally arrived as the 'absorption type cooling system for inlet air' is most suitable for prevailing atmospheric condition of karaikal region.
\end{abstract}

Keywords: Absorption chiller, Evaporative cooling, Gas turbine, Inlet air cooling, Thermodynamic analysis

\section{Introduction}

A Gas Turbine is a heat engine that uses high temperature, high pressure gas as the working fluid. The gas turbine engine consists of a compressor to raise combustion air pressure, a combustion chamber where the fuel/air mixing is burnt, and a turbine that through expansion extracts energy from the combustion gases. These cycles operate according to the open Brayton thermodynamic cycle and are referred as combustion turbines. Generally gas turbines are compact, lightweight, quick-starting, and simple to operate, they are widely used for power generation and in aircraft propulsion. The capacity of gas turbines ranges from micro size to approximately $500 \mathrm{MW}$ maximum per unit.

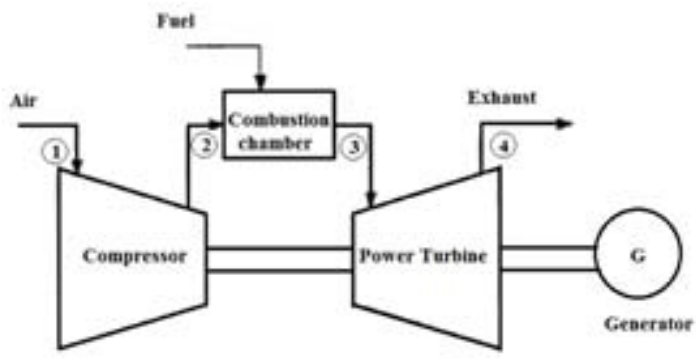

Figure 1: Schematic of the simple Gas turbine cycle

Gas Turbine power plants are responsive to load variations and are very cost effective and feasible in combined cycle operation. They are commonly used in combined cycle arrangements with steam Rankine bottoming cycle. Common fuels are NG (Natural gas), Diesel (HSD) or sometimes HFO (heavy fuel oil) to power the gas turbines.

\subsection{PPCL Gas Turbine Power Station}

The Puducherry Power Corporation Limited was incorporated with the objective of generating $32.5 \mathrm{MW}$ of Electricity (22.9 MW from Gas Turbine and 9.6 MW from Steam Turbine) at Karaikal which is one of the outlying regions of Puducherry .The required gas is obtained from the Gas wells at Narimanam in the Cauvery Basin under an agreement with the Gas Authority of India. In this study PPCL GE-BHEL Model 5001 gas turbine units is used for assessing the performance with the changes in ambient air temperature. Being a coastal town, karaikal tends to have relatively high humidity levels, the humidity ranging from $72 \%$ in June - July to around $82 \%$ in January - February. The minimum temperature is around $22^{\circ} \mathrm{C}$ during November to February, while the maximum day temperature is $38^{\circ} \mathrm{C}$ during summer months of April 1 to June. December and January are the coolest months of the year with the maximum at $28^{\circ} \mathrm{C}$ and the minimum at $22^{\circ} \mathrm{C}$ in day temperature.

\subsection{Gas Turbine Inlet Air Cooling System}

Based on the above, two approaches were applied to study this phenomenon. Firstly, actual performances were calculated by actual data acquired by the operation history of the power plant. Secondly, the performance was analyzed using thermodynamic principles by suggesting intake air cooling system. Then the results of the base case and proposed case were compared and analyzed to obtain the required level of the charge air cooling and to select a suitable type for our existing site conditions. 


\section{International Journal of Science and Research (IJSR) \\ ISSN (Online): 2319-7064}

Index Copernicus Value (2013): 6.14 | Impact Factor (2014): 5.611

\subsection{Gas Turbines Inlet Air Cooling Methods}

Different methods are available for reducing gas turbine inlet temperature. There are two basic systems currently available for inlet cooling. The first and simple system is evaporative cooling. Evaporative coolers make use of the evaporation of water to reduce the gas turbine's inlet air temperature. The second system employs various ways to chill the inlet air. In this method, the cooling medium flows through a heat exchanger located in the inlet duct to remove heat from the inlet air

\section{Evaporative Coolers}

a. Wetted-honeycomb type of medium

b. High Pressure Fog System

\section{Mechanical type coolers}

a. Vapour Compression

b. Vapour absorption Chillers.

\subsection{Evaporative Cooling System}

Evaporative coolers are used to reduce the air temperature and increase the relative humidity. In this system the density of combustion air will be increased because of reduction in the air temperature, thereby increasing the power output. However the fuel consumption of the gas turbine will be increased due to increase in density and increase in relative humidity. The evaporative coolers are mainly consists of water pump, headers, pipes, drain, valves and fittings. The water will be pumped from the water tank through the strainers and valves. The pumped water will be passed to the headers, from the headers water will be sprayed through the nozzles. The water will be sprayed from the top of the chamber and air will cross the chamber in perpendicular direction and water drops reduces the air temperature and increases the relative humidity.

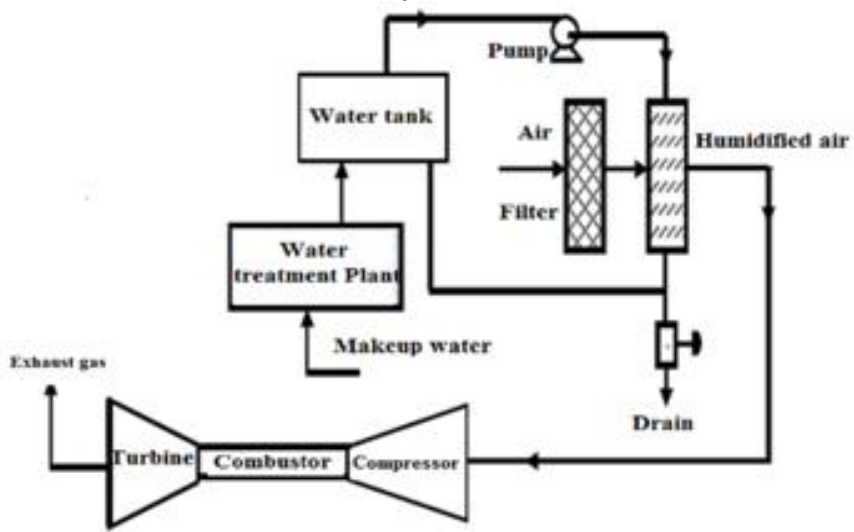

Figure 3: Gas Turbine with Evaporative cooling system

The drain water will be collected at bottom of the chamber and again reused for the cooling purpose through the filters. The cooling water should be pretreated water, otherwise will causes the filters and strainers need more maintenance. Due to evaporation of water in this process, makeup water should be provided and necessary blow-down also required.

\subsection{Absorption Cooling System}

Absorption refrigeration operates by using two fluids. Cooling occurs by evaporation similar to the vapor compression cycle. A separate chilled water system can also be used to transfer the heat. Absorption refrigeration is advantageous in cooling the inlet air because it does not require mechanical input for the operation, it requires heat input. In gas turbine operation in open cycle or combined cycle we can associate this heat input by waste heat recovery. Also lower temperatures can be achieved by absorption refrigeration compared to evaporative cooling.

Working pairs being a water / lithium bromide ( $\mathrm{LiBr}$ ) and ammonia / water. The basic principle behind this cycle lies in the reduction of vapor pressure as a refrigerant is absorbed into an absorbent. The benefit of this system is that use of low grade, often waste heat is used as the primary energy source with relatively low electrical consumption.

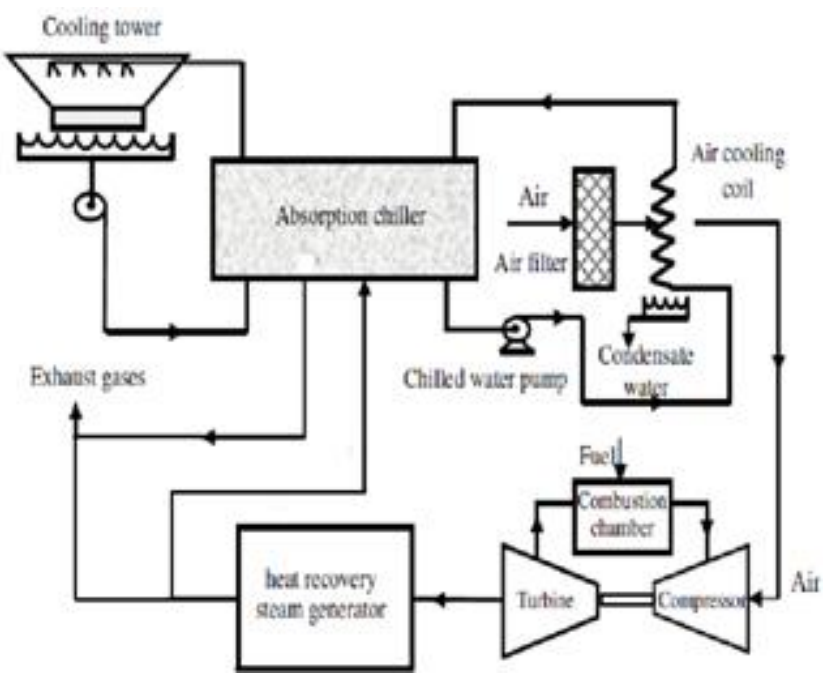

Figure 3: Gas Turbine with absorption cooling system

Among these different inlet cooling methods, this study is carried out focused on the Evaporative wetted type cooling and absorption refrigeration for the following reasons:

- As India is a moderately humid country, more frequently there is a high relative humidity level. Hence it is not recommended using fogging evaporative cooling systems. Further it is observed that high-pressure fogging require a large amount of water. The hyper-sprinkling causes compressor's blade erosion which is undesirable for plant operation.

- Vapour compression chiller consumes more power to drive compressor and pumps. The initial cost of the machine is high and maintenance cost also high.

- Wetted type evaporative cooling system is simple and cost effective system hence it is considered for analysis.

- Absorption refrigeration can achieve the cooling quickly compared to vapour compression system, and high cooling load can be gained from this method.

- The absorption cooling cycle requires mechanical input only for running small pumps. It can primarily be driven from the waste heat rejected in the form of gas turbine exhaust.

At this context, the present work focuses on the comparison of two inlet air cooling technologies. Evaporative cooling and absorption chiller are analysed at different ambient temperature and humidity conditions, and the gas turbine 


\section{International Journal of Science and Research (IJSR) \\ ISSN (Online): 2319-7064}

Index Copernicus Value (2013): 6.14 | Impact Factor (2014): 5.611

power output and thermal efficiency are compared respectively.

\section{Performance Analysis}

The performance characteristics are examined for a set of actual parameters including ambient temperature, relative humidity, turbine inlet temperature, pressure ratio etc. The performance of the gas turbine will be evaluated with each cooling method and compared with values of the base-case. The working fluid passing through the compressor is the air, and it is assumed to be an ideal gas. While in turbine the working fluid is the flue gases. The thermal analysis is performed taking into consideration of the followings:

- Pressure losses in the compressor intake and combustor and turbine exhaust ducts are as assumed to be predestined values.

- For analysis purpose Gas turbine operation is considered as open cycle mode.

- The variations of the specific heats of air and combustion products also fixed as standard as per the predestined values.

- The working fluid passing through the compressor is assumed to be an ideal mixture of air and water vapour, while that passing through the turbine is assumed to be a mixture of combustion gases and all of which are assumed to behave as ideal gases.

- It is assumed that the relative humidity of outlet air from the cooler will not exceed $100 \%$ despite the inlet air condition. The humidifying efficiency is assumed to be $80 \%$.

Table 2.1: Summary of Operating Data for the Gas Turbine Power Plant

\begin{tabular}{|c|l|c|}
\hline S. No. & \multicolumn{1}{|c|}{ Parameter } & Value Unit \\
\hline 1 & Cycle & $\begin{array}{c}\text { Single shaft, combined } \\
\text { cycle power turbine }\end{array}$ \\
\hline 2 & Pressure Ratio & 8.5 \\
\hline 3 & Turbine Inlet Temperature & $1236 \mathrm{~K}$ \\
\hline 4 & Air Flow Rate & $123 \mathrm{~kg} / \mathrm{sec}$ \\
\hline 5 & Ambient Pressure & $1.013 \mathrm{bar}$ \\
\hline 6 & Isentropic Efficiency of Compressor & $87 \%$ \\
\hline 7 & Isentropic Efficiency of Turbine & $86.8 \%$ \\
\hline 8 & Combustion Efficiency & $99.0 \%$ \\
\hline 9 & Combustion Pressure Loss & $1.17 \%$ \\
\hline 10 & Fuel FHV & Natural gas; 48235.63 \\
& & $\mathrm{KJ} / \mathrm{Kg}$ \\
\hline
\end{tabular}

\subsection{Determination of the inlet air temperature after evaporative cooling process}

The evaporative cooling is most appropriated to hot dry areas, because it utilizes the latent heat of vaporization to cool ambient temperature from the dry temperature. The achievable inlet air temperature of compressor by means of suggested evaporative cooling system can be calculated by

$$
\mathrm{T}_{1}=\mathrm{T}_{\mathrm{b}}-\varepsilon \times\left[\mathrm{T}_{\mathrm{b}}-\mathrm{T}_{\mathrm{w}}\right]
$$

Utilizing the psychometric chart corresponding wet bulb temperatures (Tw) is found. After substituting these values in Equation - 1 with evaporative cooler effectiveness $(\varepsilon)$ as $80 \%$, we can get the inlet air temperature after cooling process by assuming humidity as $75 \%$.

\subsection{The inlet air temperature after absorption cooling process}

The chillers cooling method is different of the evaporative systems. It is not limited by the ambient wet-bulb temperature and humidity. The achievable temperature is restricted only by the capacity of the chilling device to produce coolant and the ability of the coils to transfer heat. Firstly, the cooling follows a line of constant specific humidity, until the saturation point is reached, and then the water of the air begins to condense. The inlet air can be cooling to a specific constant temperature and consequently increase the power output of gas turbine. Hence we can take $15{ }^{\circ} \mathrm{C}$ as achievable inlet air temperature through absorption cooling chiller type system.

\subsection{Compressor}

A compressor gives its best performance while operating at its design point. However any other machine or system, it is also expected to operate away from the design point. Therefore calculation is made based on the actual data collected from site. The intake pressure $\operatorname{drop}\left(\Delta p_{\text {intake }}\right)$ is taken as 0.01 bar, the intake temperature taken as four different ambient temperature, specific heat ratio for air $(\gamma)$ $=1.4$ and specific heat of air at constant pressure $\left(\mathrm{C}_{\mathrm{pa}}\right)=$ $1.005 \mathrm{KJ} / \mathrm{Kg} \mathrm{k}$. For a compressor pressure ratio (for actual pressure ratio taken at site) ' $r_{p}$ ' $=8.5$

The pressure of the fluid leaving the compressor can be determined from the following equation:

Inlet pressure entering the compressor is given by

$$
\mathrm{P}_{1}=\mathrm{P}_{\mathrm{atm}}-\Delta p \text { intake }
$$

Compressor out let pressure $\mathrm{P}_{2}=\mathrm{r}_{\mathrm{p}} \times \mathrm{P}_{1}$

Using the polytrophic relations for gas ideal and knowing the isentropic efficiency of compressor the isentropic outlet temperature leaving the compressor is determined

The discharge temperature:

$$
\mathrm{T}_{2}=\mathrm{T}_{1} / \mathrm{\eta}_{\mathrm{c}} \times\left\{\left[\mathrm{P}_{2} / \mathrm{P}_{1}\right]^{\gamma-1 / \gamma}-1\right\}+\mathrm{T}_{1}
$$

Air inlet temperature $T_{1}$ of the new system is taken as four different categories. Feasible temperature after incorporating evaporative cooling is evaluated by means of psychometric chart and web based calculator.

After substituting the Compressor Inlet temperature shown above, in equation-4, we can get the compressor actual discharge temperature $T_{2}$ for all cases.

\subsection{Mass flow rate of air}

Mass flow rate is mainly depends upon the air inlet temperature and its humidity. In the gas turbine manual air flow calculation corresponding to temperature is given by the formula as per GT manual is follows:

$$
\begin{aligned}
& \text { Air flow }=\mathrm{K} \times \text { CIIFA } \times\left\{3.5 \times \mathrm{R}^{1.4257} \times\left[1-\mathrm{R}^{0.2571}\right]\right\}^{0.5} /( \\
& \left.\mathrm{T}^{0.5}\right)
\end{aligned}
$$

Note: Mass air flow rate calculation, Rankine temperature scale and psia (pounds per square inch) pressure scale are used in equation -5 , since the equation- 5 is based on older 


\section{International Journal of Science and Research (IJSR) \\ ISSN (Online): 2319-7064 \\ Index Copernicus Value (2013): 6.14 | Impact Factor (2014): 5.611}

version as per the gas turbine manual ( $\underline{\text { U.S. }}$ and $\underline{\text { Canada }}$ measure thermodynamic temperature using the Rankine scale)

Mass flow rate of inlet air for each case is calculated by substituting the values in Equation-5

Then the actual work consumed by compressor is given by Compressor work $\mathbf{W}_{\mathrm{c}}=\mathbf{M}_{\mathrm{a}} \times \mathbf{C}_{\mathbf{p a}} \times\left[\mathbf{T}_{\mathbf{2}^{-}} \mathbf{T}_{1}\right]$

\subsection{Combustor}

Heat is added to the air flowing through the gas turbine in the combustors. The air leaving the compressor enters the combustors. Its temperature increases while the pressure drops slightly across the combustors. Thus, combustors are direct-fired air heaters. The fuel is burnt almost stoichiometrically with $25 \%$ to $35 \%$ of the air entering the combustors. The combustion products mix with the remaining air to arrive at a suitable temperature for the turbine.

At a specific heat of the flue gas $\mathrm{C}_{\mathrm{pg}}=1.015 \mathrm{KJ} / \mathrm{Kg} \mathrm{k}$, out let temperature from the combustor $\mathrm{T}_{3}$, combustor efficiency taken as $\eta_{\text {combustion }}=0.99$ and a pressure drop $\left(\Delta_{\mathrm{p} \text { combustion }}\right)$ in the combustor to be $48 \mathrm{kpa}$ or ( $0.48 \mathrm{bar})$

Then outlet pressure from the combustor is determined from the following equation

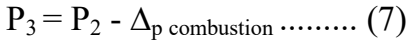

The heat delivered by combustion chamber is determined from energy balance across the combustor is given by

\subsection{Fuel mass flow rate}

$$
Q_{\text {in }}=M_{a} \times C_{p g} \times\left(T_{3}-T_{2}\right)
$$

By knowing the fuel gas heat value (FHV), the natural gas flow rate is defined as

$$
\mathrm{M}_{\mathrm{f}}=\mathrm{Q}_{\text {in }} / \mathrm{FHV} \times \eta_{\text {combustion }}
$$

The heat input $\left(\mathrm{Q}_{\text {in }}\right)$ to combustor is arrived based on the above equation- 8 and average fuel gas heat value (FHV) of Natural gas is obtained from fuel suppliers Gas Authority of India (GAIL) and combustion efficiency data is taken from manual.

\subsection{Turbine}

The power produced by the turbine is determined fixing a specific heat ratio of exhaust flue gas $(\gamma)=1.332$, invariable turbine inlet temperature $T_{1}=1236 \mathrm{k}$, turbine inlet pressure $\mathrm{P}_{3}=8.06$ bar and design back pressure DBP $=1 \mathrm{kpa}(0.01 \mathrm{bar})$

The Turbine discharge temperature $\mathrm{T}_{4}$ can be calculated using the relation

$$
{ }_{1 / \gamma} \mathrm{T}_{4}=\mathrm{T}_{3}-\eta_{\mathrm{t}} \times \mathrm{T}_{3} \times\left[1-\left(\mathrm{P}_{4} / \mathrm{P}_{3}\right)\right]^{\gamma-}
$$

Turbine discharge temperature $\mathrm{T}_{4}$ is calculated as per above relation and it is taken as same for all cases of performance calculation so as to achieve effective comparison.

Hence the Turbine power

$$
\text { (11) }
$$

$$
\mathrm{W}_{\mathrm{t}}=\mathrm{Mt} \times \mathrm{Cpg} \times\left[\mathrm{T}_{3}-\mathrm{T}_{4}\right] \text { in } \mathrm{KW}
$$

2.8 Gas turbine net power output and thermal efficiency Finally net power obtained from the gas turbine is found out using the following relation.

Net Power output obtained $\mathrm{W}_{\text {net }}=\mathrm{W}_{\mathrm{t}}-\mathrm{W}_{\mathrm{c}}$

The thermal efficiency of the gas turbine is evaluated by

Thermal efficiency $\eta_{\text {th }}=\left(W_{\text {net }} / Q_{\text {in }}\right) \times 100$

\section{Results and Discussions}

\subsection{Effect of Inlet Ambient Temperature on the Compressor Work}

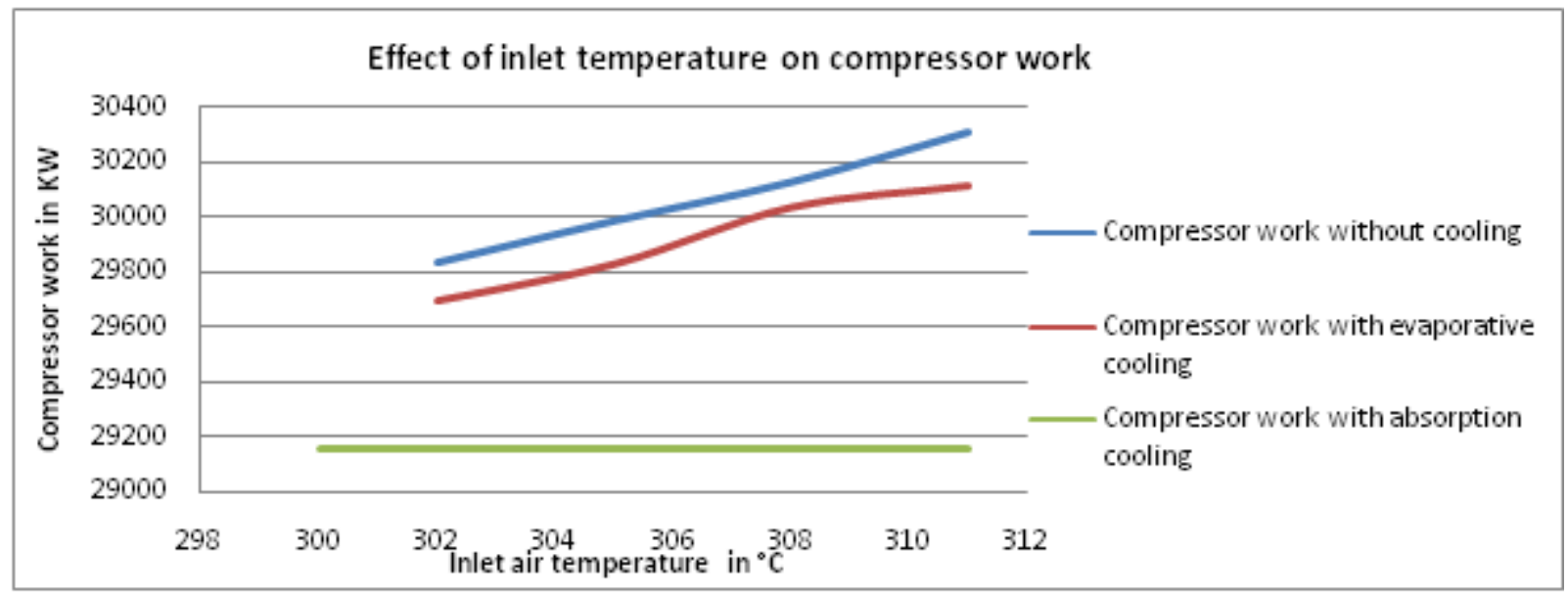

Figure 3.1: Effect of Inlet Ambient Temperature on the Compressor Work

Based on the calculation, it is observed that when ambient temperature reduces work required to compress the air is considerably reduces. This result shows the importance of low intake air temperature on gas turbine compressor power consumption. On evaporative cooling the work required to compress the inlet air is reduced about $0.52 \%$, whereas on Absorption cooling it is about $2.76 \%$ compared with base case. Mostly compressor is the more load sharing system of gas turbine if it is optimized we can get improvement on turbine efficiency.

\subsection{Effect of Inlet Air Temperature on Heat Input to Combustion Chamber}

In view of the graphical observation as observed in the fig 7.2 , it is noted that the heat input to the combustion increases

\section{Volume 5 Issue 2, February 2016}




\section{International Journal of Science and Research (IJSR) \\ ISSN (Online): 2319-7064 \\ Index Copernicus Value (2013): 6.14 | Impact Factor (2014): 5.611}

on decreasing the ambient temperature, It is because the fuel quantity supplied getting increased due to more mass flow rate of air during low ambient day and also the same limiting temperature will be reached at a lower exhaust temperature $\mathrm{T}_{\mathrm{x}}$ and it operates at maximum load with high fuel consumption. From this analysis it is observed that absorption cooling system requires more quantity of fuel than evaporative cooling system.

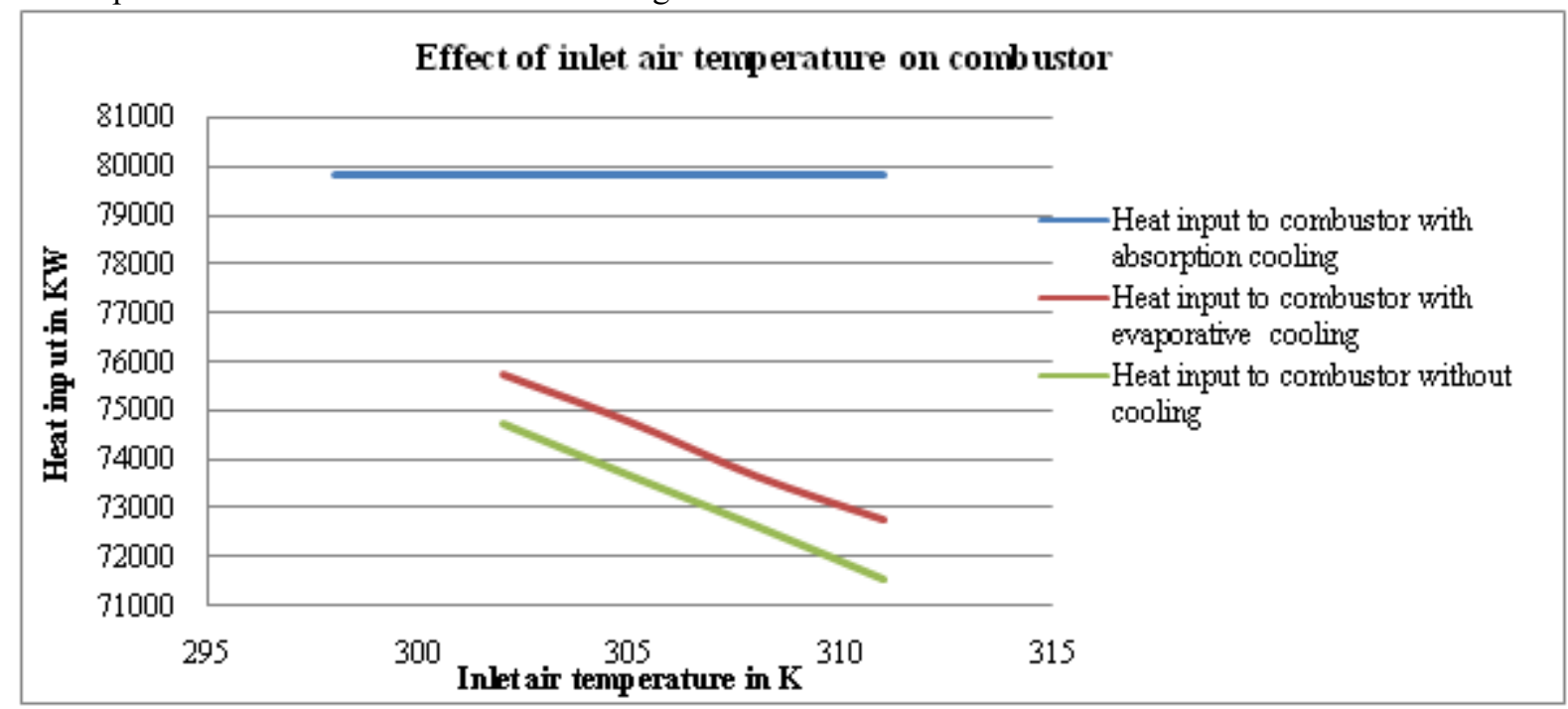

Figure 3.2: Ambient Temperature Vs Combustor Heat Input

\subsection{Effect of Ambient Temperature on Mass Flow Rate of Air}

Compressor handles a mass flow rate taken from the atmosphere and sends it to the combustion chamber where fuel is added. If incorporating evaporative cooler, the corresponding air mass flow rate increase according to the change in specific volume of air. Our experimental analysis proved the increase in mass flow rate by 0.5 to $0.8 \mathrm{~kg} / \mathrm{sec}$ for every 3 degree change in temperature. Whereas in absorption cooling system the increase in mass flow rate of air is obtained by 1.75 to $3 \mathrm{~kg} / \mathrm{sec}$ which is more than the evaporative cooling system. In view of the above, the net power obtained is getting increased by suggesting absorption type chiller in existing Gas Turbine is about $1.5 \mathrm{MW}$ more than as compared with evaporative cooling type.

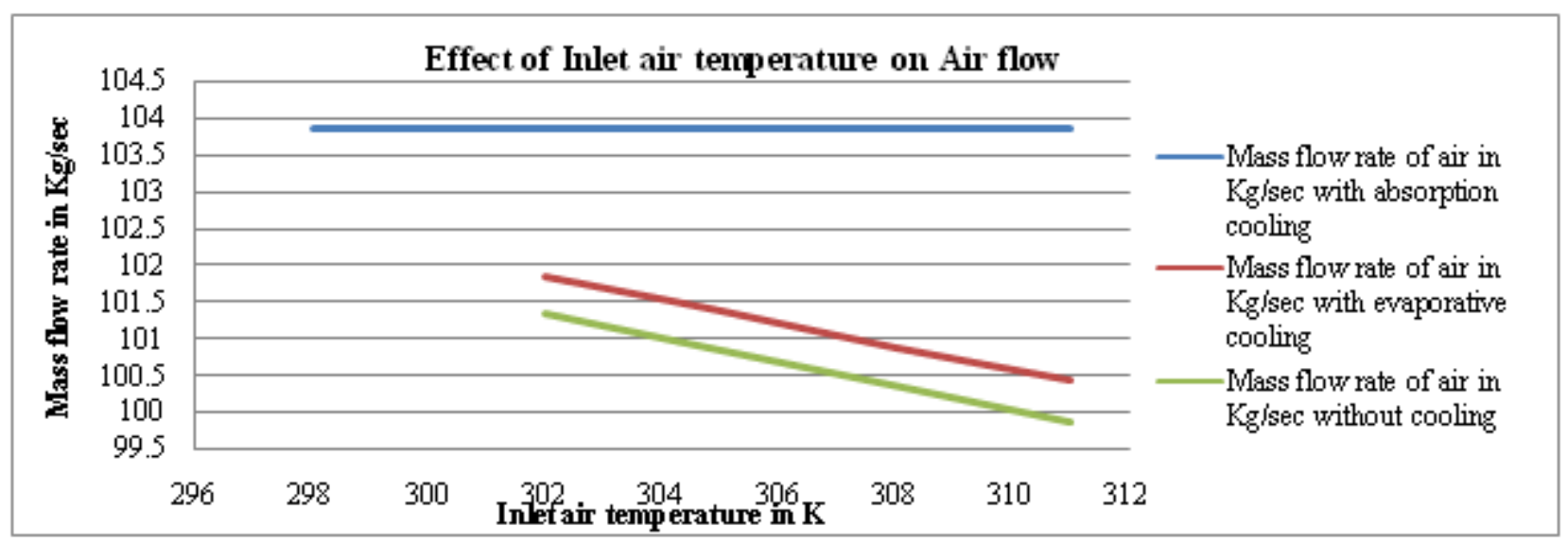

Figure 3.3: Ambient Temperature Vs Mass Flow Rate of Air

\subsection{Effect of Ambient Temperature on Gas Turbine Thermal Efficiency}

Figure 7.4 show the effect of ambient temperature on the performance of both simple gas turbine and evaporative cooling inlet conditions. Figure shows that the gas turbine thermal efficiency is affected by ambient temperature due to the change of air density and compressor work. A lower ambient temperature leads to a higher air density and a lower compressor work that in turn gives a higher gas turbine output power.It can be seen from Figure 7.4 that when the ambient temperature increases the thermal efficiency decreases. This is because, the air mass flow rate inlet to compressor increases with decrease of the ambient temperature. So, the fuel mass flow rate will increase, since air to fuel ratio is kept as constant. 
International Journal of Science and Research (IJSR)

ISSN (Online): 2319-7064

Index Copernicus Value (2013): 6.14 | Impact Factor (2014): 5.611

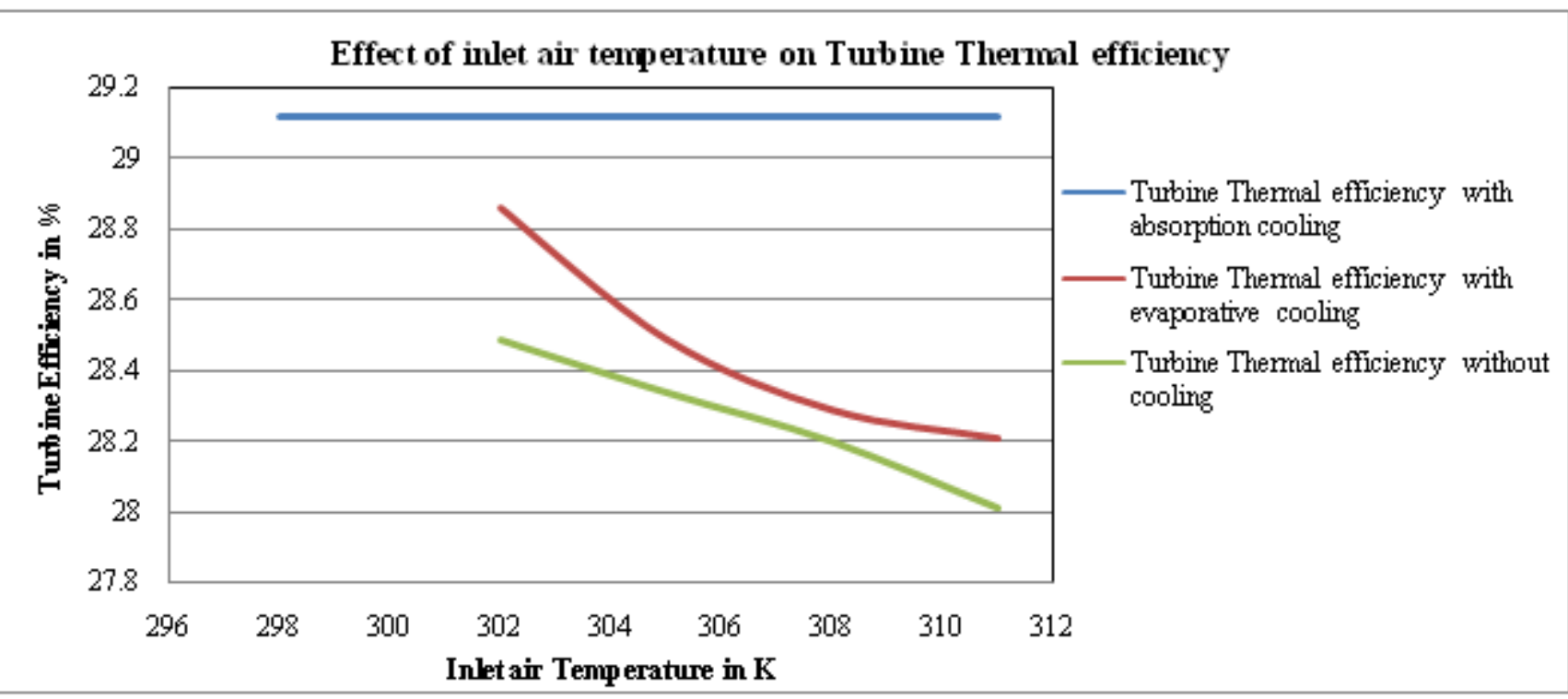

Figure 7.4: Ambient Temperature Vs Thermal Efficiency

\section{Conclusion}

Inlet air cooling systems are useful method to increase the net power generation of gas turbine power plants especially in hot climates. In this study, system performance data are analyzed with respect to ambient air conditions. First an evaporative cooling system was considered at the inlet of compressor. In this case, wet bulb temperature and relative humidity of ambient is a constraint of cooling capacity. The change in temperature obtained is $3.4{ }^{\circ} \mathrm{C}$ only. Water sources near the power plant and the quality of sprayed water are the main obstacles of evaporative coolers. Next an absorption cooling system was considered at the inlet of compressor. In this case, there is no restriction with respect to wet bulb temperature and humidity. Absorption chillers can utilizes exhaust heat to satisfy the cooling effect of inlet air.

The comparison results showed that both methods improve the power output and thermal efficiency when compared with existing system (without cooling). However the evaporative cooling method was limited by the ambient wetbulb temperature, representing a suitable solution at low ambient relative humidity inlet conditions. As in karaikal regions the average humidity during summer season is around $74.3 \%$, the power output gain obtained is only of 1.87 $\%$. Whereas by suggesting absorption chiller, we can obtain a power output gain of $9.27 \%$.The increase in thermal efficiency obtained by means of evaporative cooling is $0.37 \%$ whereas in absorption type cooling method, it is about $0.63 \%$.

On the other hand, the absorption chiller also attained a larger temperature drop $\left(14{ }^{\circ} \mathrm{C}\right.$ to $\left.23{ }^{\circ} \mathrm{C}\right)$ at different ambient conditions. Therefore, if the exhaust gas energy is available, absorption method represents a better option once it can be utilized independent of the ambient relative humidity level. However, comparing the cooled cycle and the simple cycle it was observed that for any ambient temperature and relative humidity, the cooled cycle improves all the performance parameters of the gas turbine plant. In order to select a particular cooling technique for implementation, in India energy utility sector, research including system performance and economic analysis of the cooling methods will appear to be worth and beneficial.
Abbreviations

GE General Electric

ISO International Standard Organization

PPCL Puducherry Power Corporation Limited

Symbols

$\mathrm{T}_{1} \quad$ Achievable inlet air temperature of air in ${ }^{\circ} \mathrm{C}$

$\mathrm{T}_{\mathrm{b}} \quad$ Dry bulb temperature of air ${ }^{\circ} \mathrm{C}$

$\mathrm{T}_{\mathrm{w}} \quad$ Wet bulb temperature of air in ${ }^{\circ} \mathrm{C}$

$\varepsilon \quad$ Effectiveness of Evaporative Cooler

$\mathbf{Q}_{\mathrm{CL}} \quad$ Cooling load in KW

$\mathrm{M}_{\mathrm{a}} \quad$ Mass flow of air in $\mathrm{Kg} / \mathrm{sec}$

$\mathrm{C}_{\mathrm{pa}} \quad$ specific heat of dry air at constant pressure $1.005 \mathrm{KJ} / \mathrm{Kg} \mathrm{k}$

$\mathrm{P}_{1} \quad$ Inlet air pressure entering the compressor in Bar

$\Delta p \quad$ Intake air pressure drop in bar

$\begin{array}{ll}\mathbf{W}_{\mathrm{c}} & \text { Compressor work in Kw } \\ \mathrm{C}_{\mathrm{pg}} & \text { specific heat of the flue gas } 1.015 \mathrm{KJ} / \mathrm{Kg} \mathrm{k} \\ \mathrm{P}_{3} & \text { Outlet Combustor Pressure in bar } \\ \Delta_{\mathrm{p}} & \text { Combustor pressure drop in bar } \\ \text { combustion } & \\ \mathrm{Q}_{\mathrm{in}} & \text { Heat input to the combustor in } \mathrm{Kw} \\ \mathrm{T}_{3} & \text { Turbine inlet temperature in } \mathrm{K} \\ \mathrm{C}_{\mathrm{p}} \mathrm{g} & \text { specific heat of dry air at constant pressure } \\ & 1.15 \mathrm{KJ} / \mathrm{Kgk} \\ \mathrm{M}_{\mathrm{f}} & \text { Mass flow rate of air in Kg/sec } \\ \eta_{\text {combustion }} & \text { Combustor efficiency (Taken as } 99 \%) \\ \mathrm{T}_{4} & \text { Turbine exhaust temperature } \mathrm{k} \\ \eta_{\mathrm{t}} & \text { Turbine Isentropic efficiency } \\ & \\ \mathrm{P}_{4} & \text { Turbine exhaust pressure in Bar } \\ \mathrm{DBP} & \text { Design back pressure in Bar }\end{array}$




\section{International Journal of Science and Research (IJSR) \\ ISSN (Online): 2319-7064}

Index Copernicus Value (2013): 6.14 | Impact Factor (2014): 5.611

$\begin{array}{ll}\mathrm{r}_{\mathrm{p}} & \text { Compressor pressure ratio } \\ \mathrm{P}_{2} & \text { Compressor out let pressure in bar } \\ \gamma & \text { Specific Heat Ratio } \\ \eta_{\mathrm{c}} & \text { Compressor efficiency } \\ \mathrm{K} & \text { Bell mouth constant } \\ \mathrm{CIIFA} & \text { Total inlet duct loss in psia } \\ \mathrm{R} & \text { Ratio of CPIA/CTIFA } \\ \mathrm{CPIA} & \text { Total bell mouth DP in psia } \\ \mathrm{T} & \text { Ambient Temperature in }{ }^{\circ} \text { Rankine }\end{array}$

$\mathrm{M}_{\mathrm{t}}$

$\mathrm{W}_{\mathrm{t}}$

$\mathrm{W}_{\text {net }}$

$\eta_{\mathrm{t}}$
Total mass flow fuel and air in $\mathrm{Kg} / \mathrm{sec}$

Turbine power in $\mathrm{Kw}$

Net Turbine Power output in Kw

Thermal efficiency of the turbine

\section{References}

[1] AL-TOBI, Is'haq. 2009. Performance Enhancement of Gas Turbines by Inlet Air Cooling. In: International Conference on Communication Computer and Power (ICCCP'09). Muscat, pp.165-170.

[2] Puducherry power corporation BHEL-GE Gas turbine machine manuals.

[3] APOGEE, Interactive Inc. 2013. APOGEE Interactive Energy library. [online]. [Accessed 2013]. Available from World Wide Web: $<$ http://smud.apogee.net/comsuite/content/ces/?utilid=s \&id $=1084>$

[4] B. DAWOUD, Y.H. Zurigat, J. Bortmany. 2004. Thermodynamic assessment of power requirements and impact of different gas-turbine inlet air cooling techniques at two different locations in Oman. Oman: www.sciencedirect.com.

[5] BOYCE, Meherwan P. 2002. Gas Turbine Engineering Handbook. Texas: Butterworth-Heinemann.

[6] Broad USA inc. [online]. Available from World Wide Web: <http://www.broadusa.com/>

[7] DAIBER, Paul C. Performance and Reliability Improvement for the MS5001 Gas Turbines. Atlanta: GE Power systems.

[8] EASTOP, T.D. 2002. Applied Thermodynamics for Engineering Technologists. Longman Group UK Ltd.

[9] H COHEN, GFC Rogers, HIH Saravanamuttoo. 1995. GAS TURBINE THEORY. Harlow, England: Longman Group Ltd.

[10] JOAN CARLES BRUNO, Víctor Ortega-López, Alberto Coronas. 2008. Integration of absorption cooling systems into micro gas turbine trigeneration. Elsvier. 